\title{
Effect of Malting on Nutritional Profile of Alfalfa Seeds and Development of Value Added Fermented Products
}

\author{
Sakshi Pandey ${ }^{1 *}$, Neelam Chaturvedi ${ }^{2}$ and Diksha Gupta ${ }^{2}$ \\ ${ }^{1}$ Teaching Associate at Jayoti Vidyapith Women's University, Jaipur Rajasthan, India \\ ${ }^{2}$ Department of Food Science and Nutrition, Banasthali Vidyapith, Dist-Tonk, Rajasthan, India
}

*Corresponding author: sakship98765@gmail.com

Received: $10-07-2019$

Revised: $14-10-2019$

Accepted: 29-11-2019

\begin{abstract}
The nutritive quality of legumes is poor due to deficiency of certain amino acids, low protein and starch digestibility and presence of certain anti-nutritional factor. As a result, processing techniques are adopted to overcome these problems and increases the palatability of legumes. Malting is one of the simple and inexpensive traditional processing techniques that are widely accepted for achieving desirable changes in the composition of legumes. In view of the above aspects the aim of present work was to investigate the effect of malting on nutritional profile of alfalfa seeds and development of value added fermented products. The nutritional profile (moisture, ash, protein, fat, fibre, carbohydrate, calcium and iron content) of unmalted and malted alfalfa flours were analysed with standard protocols. Fermented products viz; Dhokla and Appe were developed by incorporating malted alfalfa flour (MAF) at 10\%, 15\% and 20\% level and organoleptic evaluated by 5-point composite Score and 9-point hedonic scale. The study data revealed that malted alfalfa flour contain significantly increased content of protein (19.6\%), fibre (29.1\%), iron (39.9\%) and calcium $(93.9 \%)$ when compared to unmalted alfalfa flour at $\mathrm{P} \geq 0.05$ level. Sensory evaluation showed that fermented products developed at $10 \%$ level of incorporation of malted alfalfa flour were highly acceptable and registered insignificant difference at $\mathrm{P} \leq 0.05$ level when compared with their respective standard products. Thus, it can be concluded that the malted alfalfa seeds contain appreciable amount of nutrients that may be used in the formulation of fermented food products and advantageous in human health.
\end{abstract}

Keywords: Alfalfa, Malting. Fermentation, Appe, Dhokla

Legumes play a very important role in vegetarian diet of the Indian population. India is the largest consumer and importer of pulses in the world and they are consumed regularly in every household at least in one meal (Gujral et al. 2013). The nutritional value of legume is gaining considerable interest in developed countries because of high content of proteins with essential amino acids, complex carbohydrates, dietary fibre, unsaturated fats, vitamins and essential minerals for the human diet (Rebello et al. 2014). Epidemiological studies provide convincing evidence that a diet rich in antioxidants is associated with lower incidence of degenerative and metabolic diseases. Legumes produce primary and secondary metabolites which possess certain pharmaceutical properties that have also been reported to be associated with numerous beneficial health attributes such as hypotensive, hypocholesterolemic, antiatherogenic, anticarcinogenic, hepatoprotective and hypoglycemic properties (Ndidi et al. 2014).

Alfalfa (Medicago sativa) is a perennial species belongs to the leguminosae family. It is one of the genus and most reputed medicinal plants which has the largest cultivation area in present world because of its numerous qualities such as cold resistance, salt 
tolerance, high yield, soil amelioration and economic benefits (Shangli et al. 2017). It is considered as 'father of all plants' and green food of the millennium and one of the remarkable legumes that contain high amount of protein, calcium, vitamins in order to maintain proper functioning of the whole body (Dong et al. 2011). It also contains high amount of bioactive components such as saponins, alkaloids, flavonoids, glycosides, phytoestrogen and phenolics with various pharmacological properties such as antimicrobial, anti-inflammatory, anticancer, antihypercholesterolemic and antidiabetic (Rathee et al. 2009).

Several methods have been generally adopted to improve the nutritional and organoleptic qualities of legumes. Malting has been suggested as an inexpensive and effective way to improve the quality of legumes and for the elimination of the nutritional impediments of foods. It is a biotechnological technique which involves the controlled germination of a cereal grain (Laxmi et al. 2015) by which the quality of a cereal can be improved for both digestibility and physiological function, particularly through the breakdown of certain anti- nutrients, such as phytate, tannin and protease inhibitors (Graham et al. 2000). While fermentation is one of the oldest and most economical methods that provide a way to preserve food, destroys undesirable factors, enhance value in the area of human nutrition. Hence, in the light of the above research facts, the present study was undertaken to determine the nutritional profile of malted alfalfa seeds and development of value added fermented products.

\section{MATERIALS AND METHODS}

\section{Collection of raw sample}

Alfalfa seeds (Medicago sativa) were collected from the local market of Hald wani, Uttarakhand. The flour was prepared by malting technique which includes Soaking ( 3 h), Germination (48 h) and Kilning (4 h).

\section{Processing and preparation of malted alfalfa flour}

$500 \mathrm{~g}$ of alfalfa seeds were weighed, stored, steeped in distilled water for $3 \mathrm{~h}$ at room temperature and then completely drained of steep water using sieves. The drained seeds were then spread on a moistened jute sack and allowed to germinate at room temperature for $48 \mathrm{~h}$. The germinated grains were manually washed with distilled water, drained and oven dried at $55^{\circ} \mathrm{C}$ for $4 \mathrm{~h}$. The dried grains were milled using attrition mill, sieved and packaged in an airtight container for further analysis.

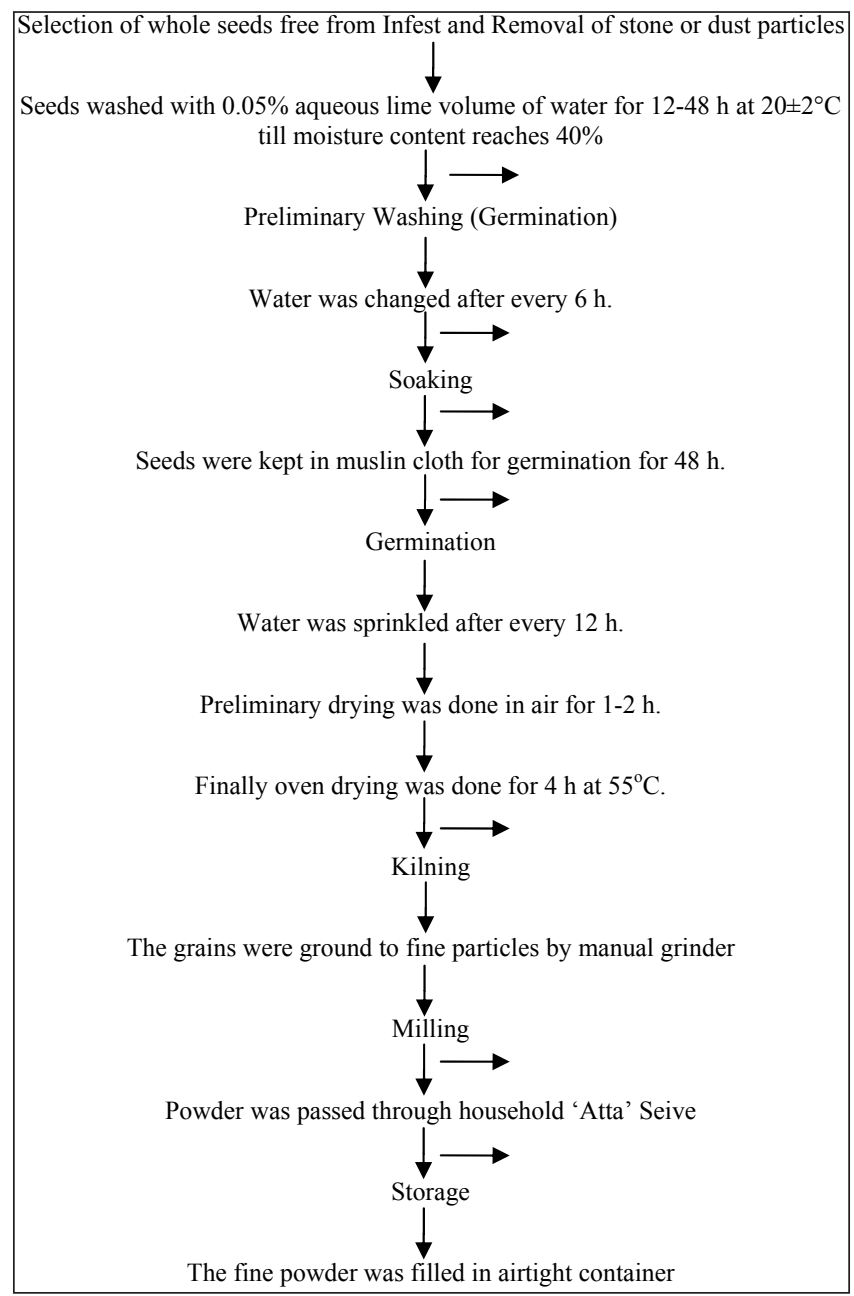

\section{Nutritional Profile}

Moisture content was determined by drying in an oven at $55^{\circ} \mathrm{C}$ to constant weight. Ash content was determined by weight difference after sample mineralization at $600^{\circ} \mathrm{C}$ for $6 \mathrm{~h}$. Fat was determined through Socs Plus system (Pelican, Model: SCS-6) by using petroleum ether. Fiber content of samples 
were determined by digesting dry sample with $1.25 \%$ $\mathrm{H} 2 \mathrm{SO} 4$, followed by $1.25 \% \mathrm{NaOH}$ solution in Fibra Plus Fiber analyzer (Pelican, Model: FES-4). Protein was determined indirectly from the analysis of total nitrogen (Crude Protein= Amount of Nitrogen $\times 6.25$ ) using Micro Kjeldhal method by Kel Plus analyzer (Pelican, Model: KES-061) and Carbohydrate content was determined by subtracting the content of protein, moisture, ash, fiber and fat from 100 (AOAC, 2005). Minerals such as, Iron content was determined by Wong's method whereas; Calcium content was determined by titration against standard potassium permanganate solution (Sharma, 2007).

\section{Product development and sensory evaluation}

The fermented products (Dhokla and Appe) were developed with their three variations by incorporating malted alfalfa flour (MAF) at different concentration assigned as 1015 and $20 \%$ respectively. The evaluation of the developed fermented products were carried out by using 5 point composite scale with respect to various attributes namely; appearance, color, texture, flavor and taste whereas, overall acceptability was analyzed by 9 -point hedonic rating scale.

\section{Statistical Analysis}

The results obtained were expressed as Mean \pm SD and Paired $t$-Test of three determinations and also statistically analyzed to ascertain its significance. The significance was estimated at ( $\mathrm{p} \leq 0.05$ level).

\section{RESULTS AND DISCUSSION}

Table 1 and Fig. 1 shows nutritional composition for moisture, ash, fat, protein, fiber, carbohydrate of unmalted and malted alfalfa flour. Low moisture content is encouraged to safeguard the product from microbial attack and enzymatic action which may prevent spoilage (Akonor et al. 2016). Unmalted and malted alfalfa flours had moisture content $(\mathrm{g} / 100 \mathrm{~g}) 7.36 \pm 0.40$ and $8.62 \pm 0.37$ respectively. This data illustrates that malted flour had significantly increased moisture content by $17.1 \%$ at $p \geq 0.05$ level when compared with unmalted flour. Similar data predicted by Gernah et al. (2011) that malted Zea mays had $9.70 \pm 0.01 \mathrm{~g} / 100 \mathrm{~g}$ of moisture content which was significantly increased by $19.7 \%$ at $\mathrm{p} \geq 0.05$ level. Ash content is directly proportional with inorganic element content of legumes. Hence, the samples with high percentage of ash contents are expected to have high concentrations of various mineral elements, which are advantage to speed up metabolic processes and improve growth and development (Fekadu et al. 2013). Unmalted alfalfa flour had higher ash content $(3.57 \pm 0.11 \mathrm{~g} / 100 \mathrm{~g})$ as compare to malted flour $(2.63 \pm 0.22)$ by $26.3 \%$ at $p \geq 0.05$ level which was comparable to the data given by Afifi et al. (2012) that germinated grains of sorghum had $1.20 \pm 0.07 \mathrm{~g} / 100 \mathrm{~g}$ of ash content which was significantly decreased by $16.0 \%$ at $p \geq 0.05$ level when compared with raw sorghum grains.

Table 1: Nutritional composition of Unmalted and Malted Alfalfa Seeds on Dry Weight Basis

\begin{tabular}{lll}
\hline $\begin{array}{l}\text { Parameters } \\
\text { (g/100g) }\end{array}$ & \multicolumn{2}{c}{ Alfalfa seeds } \\
\cline { 2 - 3 } Unmalted flour Malted flour \\
\hline Moisture & $7.36 \pm 0.40$ & $8.62 \pm 0.37(17.1 \% \uparrow)^{*}$ \\
Ash & $3.57 \pm 0.11$ & $2.63 \pm 0.22(26.3 \% \downarrow)^{*}$ \\
Fat & $2.60 \pm 0.96$ & $1.04 \pm 0.06(39.3 \% \downarrow)^{*}$ \\
Protein & $15.42 \pm 0.01$ & $18.45 \pm 0.03(19.6 \% \uparrow)^{*}$ \\
Fiber & $5.79 \pm 0.12$ & $6.48 \pm 0.22(29.1 \% \uparrow)^{*}$ \\
Carbohydrate & $65.26 \pm 0.48$ & $61.78 \pm 0.59(5.03 \% \downarrow)^{*}$ \\
\hline
\end{tabular}

Values are expressed as Mean \pm SD of triplicate determinations of unmalted alfalfa flour and malted flour on dry weight basis. * Shows significant difference at $(p \geq 0.05)$ level.

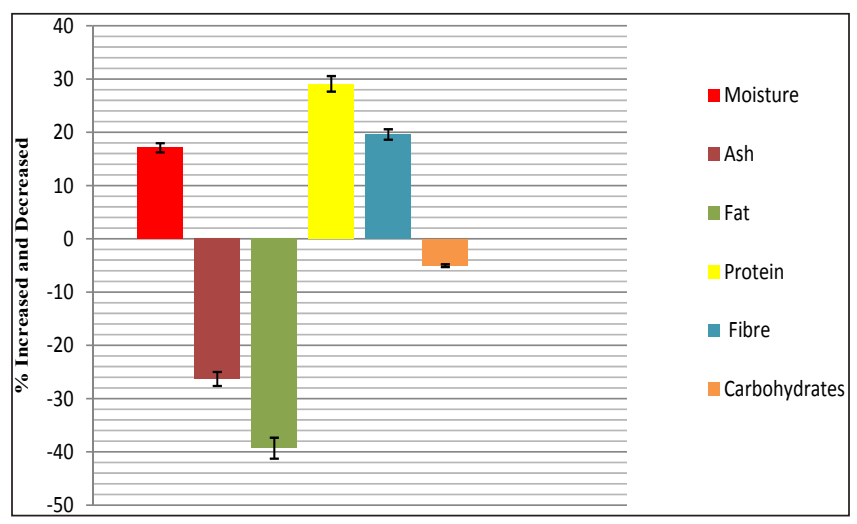

Fig. 1: Present difference of unmalted and malted alfalfa flour with moisture, ash, fat, protein, fibre, carbohydrate 
The low fat content favors in the prevention of metabolic disorders such as cardiovascular diseases, diabetes and cancer (Showemimo and Olarewaju, 2004). Fat content (g/100g) of unmalted and malted alfalfa flours was $2.60 \pm 0.96$ and $1.04 \pm 0.06$ respectively. This shows that unmalted flour had increased value by $39.3 \%$ at $p \geq 0.05$ level when compared to malted alfalfa flour. Similar data predicted by Nour et al. (2015) sprouted grains of sorghum had $1.33 \mathrm{~g} / 100 \mathrm{~g}$ of fat content which was significantly decreased by $63.6 \%$ at $p \geq 0.05$ level when compared with raw grains. Proteins are enzymes that catalyze chemical reactions and accelerate some chemical reactions (Gbile and Adesina, 2009). Protein content (g/100g) of unmalted and malted alfalfa flour was $22.1 \pm 0.01$ and $29.4 \pm 0.03$ respectively. This shows that malted alfalfa flour had significantly increased protein content by $30 \%$ at $\mathrm{p} \geq 0.05$ level. The observation is agreed with other scientific findings reported by Blessing and Gregory, (2010) that germinated Vigna radiate had $30.6 \pm 0.11 \mathrm{~g} / 100 \mathrm{~g}$ of protein content which was significantly increased by $27.07 \%$ at $p \geq 0.05$ level when compared with raw Vigna radiate.

Intake of fibre may lower the serum cholesterol level and chances of having the risk of coronary heart disease, hypertension, constipation, diabetes, colon and breast cancer (Jain et al. 2011).

Fibre content $(\mathrm{g} / 100 \mathrm{~g})$ in unmalted alfalfa seeds flour was $5.79 \pm 0.12$ which was significantly decreased by $29.1 \%$ when compared with malted alfalfa flour $(6.48 \pm 0.22)$ at $\mathrm{p} \geq 0.05$ level. Banusha and Vasntharuba, (2013) have reported that malted grain of Eleusine coracana had $4.26 \pm 0.11 \mathrm{~g} / 100 \mathrm{~g}$ of fibre content which was significantly increased by $8.12 \%$ at $\mathrm{p} \geq 0.05$ level when compared with unmalted grains. Unmalted alfalfa seeds flour had significantly increased carbohydrate content $(58.5 \pm 0.48 \mathrm{~g} / 100 \mathrm{~g})$ when compared with malted alfalfa flour $(51.8 \pm 0.59 \mathrm{~g} / 100 \mathrm{~g})$ by $11.4 \%$ at $\mathrm{p} \geq 0.05$ level which was comparable to the data given by Nwosu, (2013) that malted beans of Sphenostylis sternocarpa had $58.5 \mathrm{~g} / 100 \mathrm{~g}$ of carbohydrates content which was significantly decreased by $6.84 \%$ at $\mathrm{p} \geq 0.05$ level when compared with unmalted beans.
Table 2: Mineral composition of Unmalted and Malted Alfalfa Seeds on Dry Weight Basis

\begin{tabular}{lll}
\hline $\begin{array}{l}\text { Minerals } \\
(\mathbf{m g} / \mathbf{1 0 0 g})\end{array}$ & $\begin{array}{l}\text { Unmalted } \\
\text { flour }\end{array}$ & Malted flour \\
\hline Iron & $4.51 \pm 0.04$ & $6.31 \pm 0.096(39.9 \% \uparrow)^{*}$ \\
Calcium & $2.49 \pm 0.22$ & $4.83 \pm 0.20(93.9 \% \uparrow)^{*}$ \\
\hline
\end{tabular}

Values are expressed as Mean $\pm S D$ of triplicate determinations of unmalted alfalfa flour and malted flour on dry weight basis. *Shows significant difference at $(p \geq 0.05)$ level.

The iron and calcium content that are required for hemoglobin production and bone development (Leterme, 2002). Table 2 indicates that iron content $(\mathrm{mg} / 100 \mathrm{~g})$ of unmalted and malted alfalfa flours was $4.51 \pm 0.46$ and $6.31 \pm 0.09$ respectively. This shows that malted flour value significantly increased by $39.9 \%$ at $\mathrm{p} \geq 0.05$ level. Similar data predicted by Laxmi et al. (2015) that malted chickpea contains $45.4 \mathrm{mg} / 100 \mathrm{mg}$ of iron which was significantly increased by $17.39 \%$ atp $\geq 0.05$ level when compared with unmalted peas. The result obtained for calcium content $(\mathrm{mg} / 100 \mathrm{~g})$ was significantly higher in malted alfalfa seeds flour $(4.83 \pm 0.20)$ by $93.9 \%$ as compared to unmalted alfalfa flour $(2.49 \pm 0.22)$ at $\mathrm{p} \geq 0.05$ level that was comparable with the study reported by Plaza et al. (2003) that germinated alfalfa seeds had $3.32 \pm 0.13 \mathrm{mg} / 100 \mathrm{~g}$ of calcium which was significantly increased by $102.4 \%$ at $\mathrm{p} \geq 0.05$ level when compared with raw seeds.

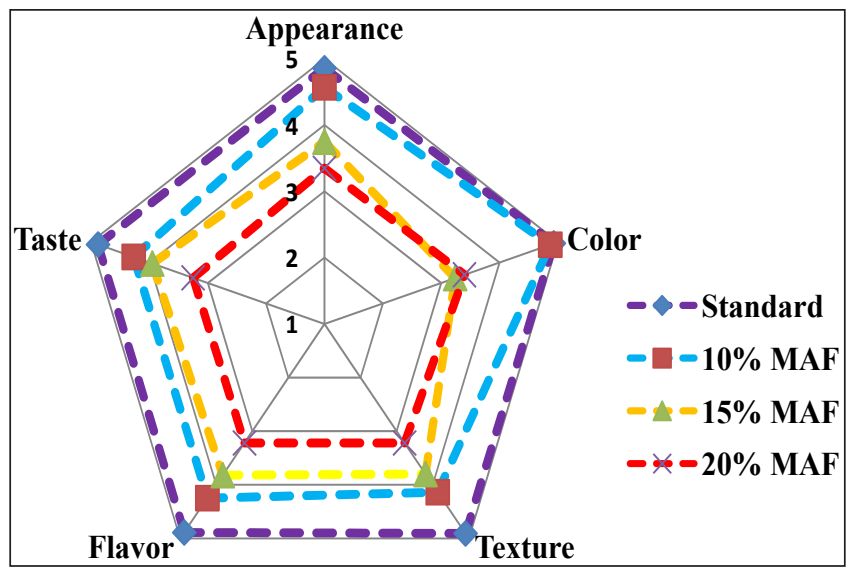

Fig. 2(a): Acceptability evaluation of Dhokla by incorporating malted alfalfa flour in term of sensory attributes 


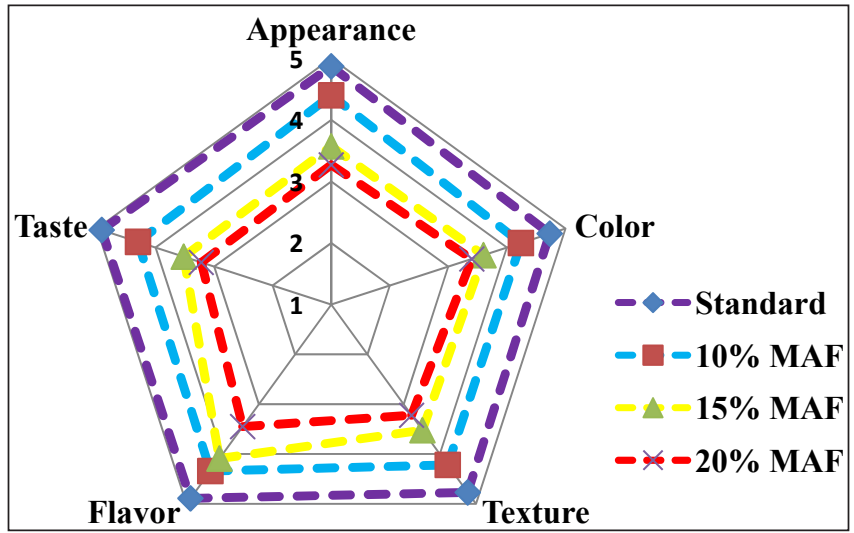

Fig. 2(b): Acceptability evaluation of Appe by incorporating malted alfalfa flour in term of sensory attributes

The fermented products viz; Dhokla and Appe were prepared by the incorporation of malted alfalfa flour (MAF) at three different variations i.e. 10, 15, and $20 \%$ respectively which were compared with their standard product as depicted in Fig. 2(a) and (b). The data showed that the mean value obtained for their standard products were ranging for Dhokla $(4.86 \pm 0.28$ to $4.93 \pm 0.24)$ and Appe $(4.77 \pm 0.38$ to $4.92 \pm 0.32$ ) in terms of all sensory attributes. Whereas, the mean values obtained for test products developed with $10 \%$ MAF were ranging for Dhokla $(4.14 \pm 0.45$ to $4.87 \pm 0.46)$ and Appe $(4.22 \pm 0.30$ to $4.41 \pm 0.07)$ and was found to be acceptable and comparable to standard products which showed insignificant difference at $\mathrm{p}<0.05$ level.

Table 3: Overall Acceptability Evaluation of Fermented Dhokla and Appe by Incorporating Malted Alfalfa Flour in terms of Sensory Attributes by 9 Point Hedonic Scale

\begin{tabular}{lllll}
\hline $\begin{array}{l}\text { Overall } \\
\text { acceptability }\end{array}$ & $\begin{array}{l}\text { Standard } \begin{array}{l}\mathbf{1 0} \% \\
\text { MAF }\end{array} \\
\text { Dhokla }\end{array}$ & $\begin{array}{l}\mathbf{1 5 \%} \\
\text { MAF }\end{array}$ & $\begin{array}{l}\mathbf{2 0 \%} \\
\text { MAF }\end{array}$ \\
Appe & $8.82 \pm 0.33$ & $8.50 \pm 0.42^{\mathrm{NS}}$ & $6.8 \pm 0.5^{*}$ & $6.4 \pm 0.58^{*}$ \\
\hline
\end{tabular}

Values are expressed as Mean \pm SD of triplicate determinations of unmalted alfalfa flour and malted flour on dry weight basis.

* Shows significant difference at ( $p \geq 0.05)$ level. NS shows nonsignificant difference at $(p \geq 0.05)$ level.

However, incorporation of $15 \%$ and 20\% MAF based products was found to be less acceptable and found to be significant at $\mathrm{p}<0.05$ level when compared to their respective standard products.

As shown in table 3 , the overall acceptability for Dhokla (8.50 \pm 0.42$)$ and Appe $(8.32 \pm 0.24)$ developed at $10 \%$ level of incorporation with MAF were found to be highly acceptable and comparable with their respective standard products and registered insignificant difference at $\mathrm{P} \geq 0.05$ level. However, other variations $(15 \%$ and $20 \%$ incorporated MAF based products) were moderately liked by the panel members and registered to be significant different at $\mathrm{p} \geq 0.05$ level.

\section{CONCLUSION}

The present finding uncovered the fact that alfalfa flour had superior nutritional and sensory characteristic. However, malting resulted in significantly increase in protein, fiber, iron and calcium content. On the other hand, fermented products such as Dhokla and Appe developed at $10 \%$ level of incorporation of malted alfalfa flour were highly acceptable and registered insignificant difference at $\mathrm{P} \leq 0.05$ level when compared with their respective standard products. Thus, it can be concluded that the malted alfalfa seeds contain appreciable amount of nutrients that may be used for the formulation of various fermented food products which could be advantageous in human health

\section{ACKNOWLEDGEMENTS}

Authors are thankful to Prof. Aditya Shastri (Vice Chancellor) of Banasthali Vidyapith for providing all the required lab facilities in department of Food Science and Nutrition that helped us for the successful completion of the project work

\section{REFERENCES}

Afify, A.E.M.R., El-Beltagi, H.S., El-Salam, S.M. and Omran, A.A. 2012. Effect of soaking, cooking, germination and fermentation processing on proximate analysis and mineral content of three white sorghum varieties (Sorghum bicolor L. Moench). Not. Bot. Horti. Agrobot., 40(2): 92-98.

Akonor, P.T., Ofori, H., Dziedzoave, N.T. and Kortei, N.K., 2016. Drying characteristics and physical and nutritional 
properties of shrimp meat as affected by different traditional drying techniques. Int. J. Food Sci. Nutr., pp. 1-5.

Association of Official Analytical Chemists, (AOAC), Official Methods of Analysis of AOAC, $18^{\text {th }}$ ed., Gaithersburg, USA, 2005.

Banusha, S. and Vasantharuba, S. 2013. Effect of malting on nutritional contents of finger millet and mung bean. AmEurasian J. Agri. Environ. Sci., 13(12): 1642-1646.

Blessing, A.I. and Gregory, O.I. 2010. Effect of processing on the proximate composition of the dehulled and undehulled mung bean [Vigna radiata (L.) Wilczek] flours. Pak. J. Nutr., 9(10): 1006-1016.

Dong, X.F., Gao, W.W., Su, J.L., Tong, J.M. and Zhang, Q. 2011. Effects of dietary polysavone (Alfalfa extract) and chlortetracycline supplementation on antioxidation and meat quality in broiler chickens. Br. Poult. Sci., 52(3): 302309.

Fekadu, H., Beyene, F. and Desse, G. 2013. Effect of traditional processing methods on nutritional composition and antinutritional factors of Anchote (Coccinia abyssinica (lam.) cogn) tubers grown in Western Ethiopia. J. Food Process. Technol., 4: 1-8.

Gbile, Z.O. and Adesina, S.K. 2009. Migerian Solanum species of economic importance. Ann. Mo. Bot. Gard., 75: 862-865.

Gernah, D.I., Ariahu. and Ingbian, E.K. 2011. Effect of malting and lactic fermentation on some chemical and functional properties of maize (Zea mays). Am. J. Food Technol., 6(5): 404-412.

Graham, R.D., Humphries, J.M. and Kitchen, J.L. 2000. Nutritionally enhanced cereals: a sustainable foundation for a balanced diet. Asia Pac. J. Clin. Nutr., 9: 591-596.

Gujral, S.H., Sharma, P., Gupta N. and Wani, A.A. 2013. Antioxidant properties of legumes and their morphological fractions as affected by cooking. Food Sci. Biotechnol., 22(1): 187-194

Jain, R.., Sharma, A. and Gupta, S. 2011. Solanum nigrum current perspectives on therapeutic properties. Altern. Med. Rev., 16(1): 78-85.

Laxmi, G., Chaturvedi, N. and Richa, S. 2015. The Impact of malting on nutritional composition of foxtail millet, wheat and chickpea. J. Nutr, Food Sci., 5: 5.
Leterme, P. 2002. Recommendations by health organizations for pulse consumption. Br. J. Nutr. Suppl., 3: 239-242.

Ndidi, U.S., Ndidi, C.U., Aimola, I.A., Bassa, O.Y., Mankilik, M. and Adamu, Z. 2014. Effects of processing (Boiling and roasting) on the nutritional and antinutritional properties of Bambara groundnuts (Vigna subterranean [L.] Verdc.) from Southern Kaduna, Nigeria. J. Food Process, pp. 1-9.

Nour, M.A.A., Ibrahim, M.A.E.M., Abdelrhman, E.E., Osman, E.F., Khadir, E.K., Hussain, F.N., Abdallatif, A.N. and Eldirany, A.A. 2015. Effect of processing methods on nutritional value of Sorghum (Sorghum bicolor L. Moench) Cultivar. Am. J. Food Sci. Health, 1(4): 104-108.

Nwosu, J.N. 2013. Evaluation of the proximate composition and antinutritional properties of African yam bean (Sphenostylis sternocarpa) using malting treatment. Int. J. Bas. Appl. Sci., 2(4): 157-169.

Plaza, L., Ancos, B. and Cano, P.M. 2003. Nutritional and health related compounds in sprouts and seeds of soyabean (Glycine max), wheat (Triticum aestivum L.) and alfalfa (Medicago sativa) treated by a new drying method. Eur. Food Res. Technol., 216: 138-144.

Rathee, P., Chaudhary, H., Rathee, S., Rathee, D., Kumar, V. and Kohli, K. 2009. Mechanism of action of flavonoids as anti-inflammtory agents: a review. Curr. Drug Targets Inflamm. Allergy, 8(3): 229-235.

Rebello, C.J., Greenway, F.L., Finley, and J.W. 2014. A review of the nutritional value of legumes and their effects on obesity and its related co-morbidities. Obesity Rev., 15(5): 392-407.

Shangli, S., Lili, N. and Kevin, F.S. 2017. The Current status, problems, and prospects of Alfalfa (Medicago sativa L.) breeding in China. Agronomy, 7: 1-11.

Sharma, S. 2007. Experimental and Techniques in Biochemistry, $1^{\text {st }}$ ed., Galgotia Publication, New Delhi.

Showemimo, F.A. and Olarewaju, J.D. 2004. Agro-nutritional determinants of some garden varieties (Solanum gilo L.). J. Food Technol, 2(3): 172-175. 